\title{
The role of EPS in the foaming and fouling for a MBR operated in intermittent aeration conditions
}

\author{
Riccardo Campo ${ }^{a}$, Marco Capodici ${ }^{\mathrm{b}}$, Gaetano Di Bella ${ }^{\mathrm{a}, *}$, Michele Torregrossa $^{\mathrm{b}}$ \\ a Facoltà di Ingegneria e Architettura, Università di Enna “Kore”, Cittadella Universitaria, 94100 Enna, Italy \\ b Dipartimento di Ingegneria Civile, Università degli Studi di Palermo, Ambientale, Aerospaziale, dei Materiali, Scuola Politecnica, Viale delle Scienze ed 8 , \\ 90128 Palermo, Italy
}

\section{A R T I C L E I N F O}

\section{Article history:}

Received 18 April 2016

Received in revised form 29 August 2016

Accepted 16 November 2016

Available online 18 November 2016

\section{Keywords:}

IA-MBR

Filamentous bacteria

Foaming

Fouling

EPS

\begin{abstract}
A B S T R A C T
This work investigates the causes of foaming and fouling in an Intermittent Aerated - Membrane BioReactor (IA-MBR) used for wastewater treatment. The experiment was divided into three periods with different aerated regimes expressed with different $t_{\text {aeration }} / t_{\text {cycle }}$ ratio (Period I: $60 \mathrm{~min} / 180 \mathrm{~min}$, Period II: $80 \mathrm{~min} / 180 \mathrm{~min}$, Period III: $30 \mathrm{~min} / 90 \mathrm{~min}$ ).

The advanced foaming tests used allow the study of the role of extracellular polymeric substances (EPSs) on foaming and fouling. In general, in the Periods I and II, good correlations between the EPSs and the Modified Scum Index without purification $\left(\mathrm{MSI}_{0}\right)$ and the Foam Power were observed. The results shown that the filamentous microorganisms, which mainly grew in the Period III, play also a key factor in the foaming and fouling. In particular, when a net proliferation of filamentous bacteria occurred (during period III with a higher number of cycles per day) both EPSs concentration and filamentous abundance influence the modified scum index obtained after two purification steps $\left(\mathrm{MSI}_{2}\right)$. Finally, the processing data show that the EPSs hampered also the membrane filtration but improve the pre-filtration action of cake layer. On the other hand, the co-presence of EPSs and filamentous bacteria reduced the effect o cake layer as pre-filter.
\end{abstract}

(c) 2016 Elsevier B.V. All rights reserved.

\section{Introduction}

Membrane Bioreactors (MBRs) represent nowadays a wellconsolidated advanced available technology in order to comply with stringent mandatory requirements in terms of quality standards of treated wastewater. Indeed, MBR systems guarantee a higher effluent quality also in terms of pathogenic bacteria removal, a lower ecological footprint and a lower sludge production if compared to a conventional activated sludge (CAS) system. However, the greatest downside of MBRs is represented by the occurrence of fouling and foaming phenomena [1]. Membrane fouling consists of the deposition of particles on the membrane surface or colloidal particles within the pores of the membrane. The tangible consequence of fouling is represented by an increase of transmembrane pressure (TMP) yielding a reduction of permeability and thus a decreasing effluent flow [1]. Four groups of factors affect membrane fouling: membrane materials, mixed liquor features, influent wastewater composition and operating conditions such as

\footnotetext{
* Corresponding author.

E-mail address: gaetano.dibella@unikore.it (G. Di Bella).
}

sludge retention time (SRT), hydraulic retention time (HRT) and food to microorganism ratio (F/M) [2-4]. Particularly, the membrane fouling is strongly influenced by mixed liquor features. More in detail, among others parameters, sludge viscosity, mixed liquor suspended solids (MLSS) concentration, presence and abundance of filamentous bacteria, extracellular polymeric substances (EPSs) and soluble microbial products (SMPs) concentrations are recognized to be the key factors affecting the membrane fouling [5]. Despite many authors outlined that membrane fouling is promoted by high EPS concentrations [6,7], there is still uncertainty whether fouling results mainly influenced by proteins or polysaccharides fraction of EPS and SMP. Such uncertainty is likely due to differences in experimental methods available for EPS content assessment and also to the different configuration of MBR treatment plants [3,8].

On the other hand, the foaming represents, as well as fouling, another downside of MBRs that can lead to a significant decreasing of biological performances of MBRs and also to a decrease in membrane filtration efficiency [9]. Foaming arises as a viscous layer on the surface of wastewater treatment plant reactors; it results in a floating biomass that can cause serious operational problems to the treatment process. In particular, it is possible to distinguish two different kind of foaming: biological foaming and chemical 
foaming. The biological foaming trigger factor is recognized to be the unbalanced $\mathrm{F} / \mathrm{M}$ ratio; while the chemical foaming is attributed to a loading shock caused by the presence of synthetic surfactants [10]. Among the various kind of microorganisms traceable in the activated sludge, a significant presence of Microthrix parvicella and Nocardioforms has been observed using conventional microscopy during biological foaming occurrence. For such reason, the aforementioned microorganisms have been defined "foam forming bacteria" [11]. Furthermore, other studies outlined also the presence of other bacteria species during foaming occurrence. For this reason, bacterial strains such as the Eikelboom Type 0092 have been defined "not famous foam-forming bacteria" [9,11].

Despite the foaming in CAS is attributed to the abundance of the aforementioned strains, it has to be stressed that foaming in MBR systems can also occur in the absence of "foam-forming" or "not famous foam-forming" microorganisms. In these cases the foam abundance was attributed to the concentration of the protein fraction of EPS [12]. However, both EPSs and filamentous bacteria influence the sludge hydrophobicity and therefore impact on foaming occurrence. Although the foaming occurrence can seriously affect the correct working of a MBR, studies dealing with foaming in MBRs are scarce $[9,12,13]$. Furthermore, foaming occurrence can be encouraged by the implementation of new management strategies such as the Intermittent Aeration (IA). Although such process can offer several advantages [14,15], the intermittent aeration impact on microorganisms can result in a proliferation of foam-forming microorganisms such as filamentous bacteria. In details, the IA process consists of alternating aerobic and anoxic phases within the same stirred reactor. The implementation of such management strategy allows achieving the ammonia oxidation as well as the nitrate reduction saving energy. Indeed, the air supply necessary to the bioreactor result decreased and also the absence of return activated sludge rich in nitrates from nitrification to denitrification yield the IA a cost effective solution [15]. However, the presence of the anoxic phase can seriously impact in the strains development favoring the proliferation of foam-forming microorganisms like filamentous bacteria [14]. Bearing in mind the previous observations, and considering that extensive studies on Intermittent Aerated- Membrane BioReactor (IA-MBR) are lacking, the present study aims to investigate the fouling and foaming mechanisms in an IA-MBR system treating domestic wastewater. Specific foam tests and a detailed fouling tendency assessment have been carried out in order to outline the roots of both phenomena in IA-MBR systems. Furthermore, a detailed investigation focused to highlight the influence exerted by other parameters, such as EPS and SMP fractions and concentration, sludge viscosity, TSS concentration and filamentous microorganisms' abundance has been reported, improving the knowledge about these two drawbacks of this new and innovative MBR configuration.

\section{Material and methods}

\subsection{Experimental setup}

The pilot plant was built at Palermo municipal wastewater treatment Plant of "Acqua dei Corsari" and it was the same as that used by Capodici et al. [15]. In particular, the IA reactor $(400 \mathrm{~L})$, the MBR (50 L) tank and the Oxygen Depletion Reactor (ODR) (28 L), mainly composed the pilot plant. The first one was provided with aeration and stirring devices; the MBR reactor was downstream the IA reactor and it was continuously aerated in order to mitigate the membrane fouling; the ODR reactor was continuously stirred in order to avoid TSS settling. A logical scheme of the Pilot plant is shown in Fig. 1.

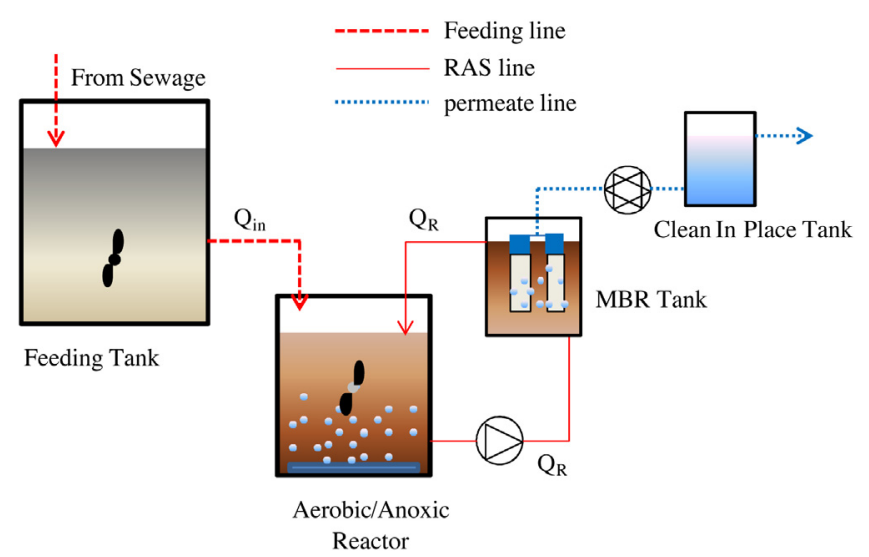

Fig. 1. Pilot Plant Lay-out.

Throughout all the experimental period, the following most relevant operational parameters were measured: Dissolved Oxygen (D.O.), pH, Oxidation Reduction Potential (O.R.P.). They were all monitored on-line by means of probes appropriately located in the different sections of the pilot plant [15].

The temperature was not regulated and was affected by the environmental conditions (room temperature): however, the variation was relatively small, changing from 18 to $24^{\circ} \mathrm{C}$ during the experimental period.

The MBR compartment was equipped with two ultrafiltration (UF) hollow fiber GE Zenon ZW10 ${ }^{\circledR}$ modules (nominal surface of single membrane unit: $0.93 \mathrm{~m}^{2}$; pore dimension: $0.04 \mu \mathrm{m}$ ) in a submerged configuration.

The durations of suction and backwash were set to 9 and $1 \mathrm{~min}$, respectively, with a total filtration cycle of $10 \mathrm{~min}$. The plant was fed continuously and the permeate flux from each membrane was equal to $20-23 \mathrm{~L} \mathrm{~m}^{-2} \mathrm{~h}^{-1}$; while the net permeate flux was equal to $17-19 \mathrm{~L} \mathrm{~m}^{-2} \mathrm{~h}^{-1}$.

The transmembrane pressure (TMP) was measured by means of analogical vacuum-meters connected to the upper heads of the membrane modules. TMP data were acquired with two data-loggers connected to the vacuum-meters, stored and then post-processed.

The experimental campaign, which lasted 120 days, was divided into three periods with different aeration regimes [15]. In details, Period I (lasted 57 days) had a $180 \mathrm{~min}$ cycle length $\left(t_{\text {cycle }}\right)$ with $60 \mathrm{~min}$ of aeration $\left(\mathrm{t}_{\mathrm{aeration}}\right)$ and $120 \mathrm{~min}$ without aeration $\left(t_{\text {aeration }} / t_{\text {cycle }}=60 / 180\right)$. In period II (lasted 47 days $)$ the cycle length was the same as that of period I and the $t_{\text {aeration }} / t_{\text {cycle }}$ ratio was equal to 80/180. Finally, period III (lasted 16 days) was characterized with a cycle length of $90 \mathrm{~min}$ with $\mathrm{t}_{\text {aeration }} / \mathrm{t}_{\text {cycle }}=30 / 90$. During the not-aerated phase, the mixed liquor was continuously mixed to avoid Suspended solids settling. The main operational parameters are reported in Table 1.

Biochemical oxygen demand (BOD5), chemical oxygen demand (COD), soluble COD, ammonium (NH4-N), nitrate ammonium (NO3-N), nitrite ammonium (NO2-N), total suspended solids (TSS) and volatile suspended solids (VSS) were measured three times per week in order to evaluate the pilot plant performance, according to Standard Methods [16].

\subsection{Foaming test and filamentous investigations}

Proposed foam tests and characterizations can be categorized as:

1) Quality test: Foaming rate and foam power;

2) Quantity test: Modified Scum Index; 
Table 1

Main operational parameters.

\begin{tabular}{|c|c|c|c|c|c|c|c|}
\hline Period & $\mathrm{n}^{\circ}$ cycles/day & Ox/Cycle $[\mathrm{min} / \mathrm{min}]$ & Anox/Cycle [min/min] & $\mathrm{F} / \mathrm{M}\left[\mathrm{kg} \mathrm{BOD}_{5} \mathrm{~kg}^{-1} \mathrm{VSS} \mathrm{d}^{-1}\right]$ & $\operatorname{COD}\left[\mathrm{g} \mathrm{m}^{-3}\right]$ & $\mathrm{NH}_{4}-\mathrm{N}\left[\mathrm{g} \mathrm{m}^{-3}\right]$ & $\operatorname{MLSS}\left[\mathrm{kg} \mathrm{m}^{-3}\right]$ \\
\hline I & 8 & $60 / 180$ & $120 / 180$ & $0,08 \pm 0.02$ & $380 \pm 48$ & $29 \pm 5$ & $\sim 2.7$ \\
\hline II & 8 & $80 / 180$ & $100 / 180$ & $0,06 \pm 0.01$ & $483 \pm 25$ & $23 \pm 3$ & $\sim 4.3$ \\
\hline III & 16 & $30 / 90$ & $60 / 90$ & $0,05 \pm 0.01$ & $414 \pm 34$ & $19 \pm 5$ & $\sim 3.7$ \\
\hline
\end{tabular}

3) Microscopic observation: Filamentous bacteria identification and abundance.

Generally, foam quality is measured on site by means of a specific apparatus. To define the foam stability and "geometric" characteristics (thickness and features), the Foaming Rate $\left(\mathrm{FM}_{R}\right)$ is used according to Blackall's method [17]. The $\mathrm{FM}_{R}$ value is measured by pouring $50 \mathrm{~mL}$ of activated sludge into a $40 \mathrm{~mm}$ diameter $\times 500 \mathrm{~mm}$ high glass cylinder and bubbling gas through it via a $40-90 \mu \mathrm{m}$ pore size diffuser at $200 \mathrm{~mL} \mathrm{~min}^{-1}$.

Foam characteristics are recorded in terms of its volume, bubble size, speed of formation and time taken for the foam to collapse after aeration has ceased (Table 2 ).

Foam Power (FP) evaluates the foam potential/stability of MBR activated sludge in accordance with the concepts used in food science. FP is defined as "the consumed sample volume $(\mathrm{mL})$ from foaming by $1 \mathrm{~L}$ of aeration" [12]. $100 \mathrm{~mL}$ of activated sludge sample is placed in a transparent $7 \mathrm{~cm}^{2}$ cross-section (A) vertical cylinder and aerated for $30 \mathrm{~s}(\mathrm{~T})$ at an air flow $\left(\mathrm{Q}_{\text {Air }}\right)$ of $5 \mathrm{~L} \mathrm{~min}^{-1}$. The FP is then determined from the difference in the interface levels of the sample liquid and foam before and after aeration $\left(\mathrm{H}_{0}\right)$ :

$\mathrm{FP}=\frac{\mathrm{A} \cdot \mathrm{H}_{\mathrm{O}}}{\mathrm{T} \cdot \mathrm{Q}_{\text {Air }}}$

While somewhat rudimentary, $\mathrm{FM}_{\mathrm{R}}$ measurement is useful for quickly assessing the extent of foaming risk (none for $\mathrm{FM}_{R}=0$; overt/onerous for $\mathrm{FM}_{R}=6-7$ ). By contrast, FP is scientifically rigorous, and essential for analysis of foaming potential and prediction of foaming risk. Furthermore, FP has been closely correlated with EPS concentration [9], and so can be indirectly associated to the physiology of the activated sludge and with other phenomena dependent on them (such as membrane fouling rate). However, both tests are simple and can be conducted directly in situ with similar simple equipment.

More useful for foaming assessment in an MBR plant is the Modified Scum Index (MSI) [10]. The MSI allows the quantification of the foam fraction from EPS (generally more abundant but less stable foam) compared with that due to the presence of filamentous bacteria (usually lower in mass but more highly stable).

MSI is determined using a 2-l aliquot of activated sludge, taken from the aeration tank, which is placed in the flotation cell and aerated at an intensity of $10 \mathrm{~L}_{\mathrm{air}} \mathrm{L}^{-1} \mathrm{~h}^{-1}$ for $15 \mathrm{~min}$ to form a thick, stable layer of scum. On ceasing aeration the scum layer is separated
Table 3

MSI classification.

\begin{tabular}{|c|c|c|c|c|}
\hline & \multirow{2}{*}{$\begin{array}{l}\text { Effect of scum flotation step } \\
\mathrm{MSI}_{0}[\%]\end{array}$} & \multicolumn{3}{|c|}{ Effect of scum purification step } \\
\hline & & $\mathrm{MSI}_{1}[\%]$ & $\mathrm{MSI}_{2}[\%]$ & $\mathrm{MSI}_{3}[\%]$ \\
\hline Low & $0-10$ & $0-10$ & $0-7.5$ & $0-5$ \\
\hline Moderate & $10-15$ & $10-15$ & $7.5-12.5$ & $5-10$ \\
\hline Serious & $15-25$ & $15-20$ & $12.5-17.5$ & $10-25$ \\
\hline Excessive & $>25$ & $>20$ & $>17.5$ & $>15$ \\
\hline
\end{tabular}

from the non-floating sludge and the test repeated several times (depending on the filamentous bacteria content) on the residual unfloated material until all of the foam-forming micro-organisms are transferred into the scum. With each step the extracted scum is stored. This first phase is called "flotation step". The portion of scum separated in this phase contains the foam produced by both the EPS contribution and the growing biomass. The dry mass of recovered scum can be determined and the $\mathrm{MSI}_{0}$ calculated as:

$$
\text { MSI }=\frac{\text { Mass of scum recovered }}{\text { Mass of Suspended Solids in the sample }} \times 100
$$

Following the flotation step, the floating scum is placed back in the flotation cell and re-suspended with water to a total volume of $2 \mathrm{~L}$. Subsequently, the "purification step" is performed under controlled aeration conditions for $15 \mathrm{~min}$ and the process of resuspension and dilution (with pure water) is repeated, with steps of $15 \mathrm{~min}$, until the amount of foam formed is constant. These portions contain only the foam-forming biomass. The equation above provides the Scum Index for each purification step in the step-bystep process ( $\mathrm{MSI}_{1}, \mathrm{MSI}_{2}, \mathrm{MSI}_{3}$, etc) to gauge foaming propensity (Table 3) based on determinations using simple equipment (Fig. 2).

In general, it has been demonstrated that the dilution of the separated scum samples could have a negative influence on the original impact of EPS concentration. For this reason, it is believed that the $\mathrm{MSI}_{0}$ represents mainly the effect of foaming due to EPS. Conversely, purifying the foam by dilution and re-suspension isolates the contribution from filamentous bacteria.

Concerning microscopic investigation, the abundance and dominance of filamentous micro-organisms by microscopic analysis can be estimated using the criteria suggested by Jenkins et al. [18]. This method is based on observing morphological and physiological characteristics of bacteria, including branching, motility, filament shape length and diameter, location, growth of attached

Table 2

Foaming Rate classification.

\begin{tabular}{|c|c|}
\hline FR & Effects \\
\hline 0 & Reaction to aeration as for pure water. Bubbles break surface but are unable to foam or have no stability. \\
\hline 1 & $1-3 \mathrm{~cm}$ of foam with fragile, ill-formed bubbles. Insufficient stability of foam films. Immediate collapse on aeration being halted. \\
\hline 2 & $\begin{array}{l}\text { Intermittent films sufficiently stable to last for }>5-10 \text { s. Usually generated from a fragile foam structure of limited height. Films unstable on aeration being } \\
\text { halted. }\end{array}$ \\
\hline 3 & $\begin{array}{l}\text { Foaming (bubbles about } 1 \mathrm{~cm} \text { dia.) to } 3-8 \mathrm{~cm} \text { height. Infrequent regular film formation, with both film and foam semi-stable on aeration being halted. Films } \\
\text { have } 10-30 \mathrm{~s} \text { stability. }\end{array}$ \\
\hline 4 & $\begin{array}{l}\text { Initially } 8-15 \mathrm{~cm} \text { of foam (about } 1 \mathrm{~cm} \text { dia. bubbles) with stable films being formed at regular intervals. Body of the foam and films stable for } 3-5 \text { min once } \\
\text { aeration ceases. }\end{array}$ \\
\hline 5 & Formation of stable foam $5-10 \mathrm{~cm}$ in height within $2 \mathrm{~min}$; after which collapse to $3-5 \mathrm{~cm}$ height, which is stable when aeration is halted. No films. \\
\hline 6 & $\begin{array}{l}\text { Stable foam } 15-30 \mathrm{~cm} \text { in height with no film. Bubble size of } \sim 0.5 \mathrm{~cm} \text { during production, increasing to } 2-3 \mathrm{~cm} \text { dia. within } 3-5 \mathrm{~min} \text { from time that aeration is } \\
\text { halted. }\end{array}$ \\
\hline 7 & $\begin{array}{l}\text { Dense stable foam }>30 \mathrm{~cm} \text { over } 2 \mathrm{~min} \text { aeration. Bubble size about } 0.3 \mathrm{~cm} \text { during production of foam and max. } 1 \mathrm{~cm} \text { dia. within } 3-5 \mathrm{~min} \text { after aeration is halted. } \\
\text { Foam is sufficiently stable to show no change in height } 10-15 \mathrm{~min} \text { after aeration is halted. }\end{array}$ \\
\hline
\end{tabular}




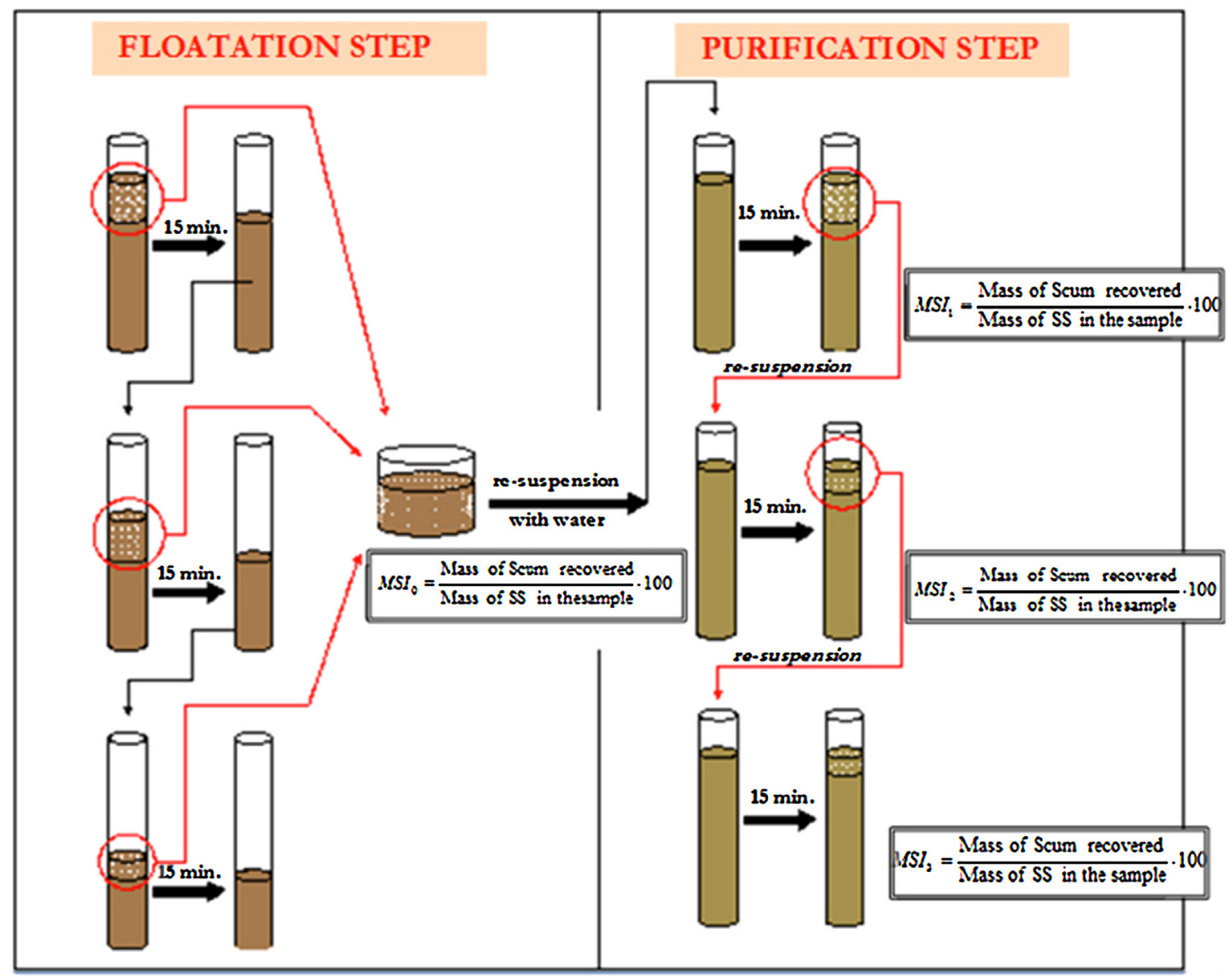

Fig. 2. MSI protocol.

epiphytic bacteria, sheath, cell septa, cell shape, floc size, sulphur deposits, and Neisser and Gram staining. The abundance of filamentous micro-organisms $(\mathrm{Ab})$ is evaluated using the subjective "scoring" of the filaments according to the index proposed by Jenkins et al., assigning a numerical value to the presence of filaments on a scale from 0 to 6 [18].

More specifically, the quantitative estimation of foam-forming micro-organisms can be calculated using a "fast method". A $50 \mathrm{~mL}$ sample is placed on the slide and the sample stained (Gram and Neisser) to identify the number of Gram and Neisser positive filaments. This is based on the number of intersections of a certain type of positive filament detected along with the total number of such positive filaments per unit area of the microscope slide. The mean number of intersections across five samples $\left(X_{A V G}\right)$ is normalised against the total mass of volatile suspended solids (VSS) in the microscopic sample ( $V$ in $\mu \mathrm{L}$ ) and corrected for the magnification $M$ to produce the Normalized Intersections Number (NIN):

$\mathrm{NIN}=\frac{\mathrm{X}_{\mathrm{AVG}} \cdot \mathrm{M}}{\mathrm{VSS} \cdot \mathrm{V}} \cdot 10^{6}$

where the $10^{6}$ factor converts $\mu \mathrm{l}$ to $\mathrm{L}$.

\subsection{Fouling analysis}

The membrane fouling has been investigated by mean of the "Resistances in Series Model" [7]. More specifically, the protocol based on the physical cleaning approach has been used to define the characteristic resistances deriving from the main fouling mechanisms. In detail, the adopted cleaning protocol was characterized by a series of different steps and actions reproduced almost identically as better outlined in the following.

1 First, permeate flux and TMP are measured during normal plant operations, before the cleaning action. On the basis of these values, the total resistance to filtration can be evaluated $\left(R_{t o t, 1}\right)$, according to Eq. (4):

$\mathrm{R}_{\mathrm{tot}, 1}=\frac{\mathrm{TMP}_{1}}{\mathrm{~J}_{1} \cdot \mu}$

where $J_{1}$ is the permeate flux of the fouled membrane $\left[\mathrm{m}^{3} \mathrm{~m}^{-2} \mathrm{~s}^{-1}\right]$, $\mathrm{TMP}_{1}$ is the transmembrane pressure in the same conditions [Pa], $\mu$ is the permeate viscosity [Pa s] that is almost equal to that of water at working temperature.

2 Afterwards, the membrane is extracted from the bioreactor and physically cleaned through 3 operational steps. Firstly, the membrane is rinsed with tap water at $0.4-0.5$ bar for $15 \mathrm{~min}$, gently rubbing the membrane surface (or the membrane fibers in the case of hollow fiber modules). Thereafter, the membrane is cleaned in pure water by means of membrane shaking, either mechanical (for small membrane modules used in bench scale plants) or manual (for bigger modules used in pilot plant applications). Finally, $5 \mathrm{~min}$ rinsing with ultrapure water (at low pressure, $<0.2$ bar) is carried out.

3 Subsequently, the cleaned membrane is immersed in clean water and subjected to a normal filtration cycle (with the same operational flux and eventually with ordinary backwashing, if any) 
in order to measure the resistance to filtration in clean water ( $\mathrm{R}_{\mathrm{tot}, \mathrm{cw}}$ ), according to Eq. (5):

$\mathrm{R}_{\mathrm{tot}, \mathrm{cw}}=\frac{\mathrm{TMP}_{\mathrm{cw}}}{\mathrm{J}_{\mathrm{cw}} \cdot \mu}$

where $\mathrm{J}_{\mathrm{cw}}\left[\mathrm{m}^{3} \mathrm{~m}^{-2} \mathrm{~s}^{-1}\right]$ and $\mathrm{TMP}_{\mathrm{cw}}[\mathrm{Pa}]$ are the permeate flux and the transmembrane pressure in clean water after physical cleaning; $\mu$ is the water viscosity [Pa s].

4 The cleaned membrane is thereafter immersed in the bioreactor and then subjected to normal filtration cycles (with the same fluxes and eventually ordinary backwashing with an average flow rate next to $900 \mathrm{~mL} \mathrm{~min}^{-1}$ ). It is worth noting that the entire process of physical cleaning had a short duration (about $1 / 2-1 \mathrm{~h}$ ) during which the MLSS concentration was assumed to be almost constant. Thus, it is possible to evaluate the final total resistance to filtration ( $\left.\mathrm{R}_{\mathrm{tot}, 2}\right)$, according to Eq. (6):

$\mathrm{R}_{\mathrm{tot}, 2}=\frac{\mathrm{TMP}_{2}}{\mathrm{~J}_{2} \cdot \mu}$

where $\mathrm{J}_{2}$ is the permeate flux during filtration of the same mixed liquor as that of step 1 , after membrane physical cleaning $\left[\mathrm{m}^{3} \mathrm{~m}^{-2} \mathrm{~s}^{-1}\right], \mathrm{TMP}_{2}$ is the transmembrane pressure under the same conditions [Pa], whereas $\mu$ is the permeate viscosity [Pa s].

The cake contribution, due to either reversible $\left(R_{C, \text { rev }}\right)$ or irreversible $\left(R_{C, i r r}\right)$ phenomena, can be computed, after cleaning, according to the steps $2-3$ of the aforementioned protocol. In this context, the total resistance can be expressed basing on the specific deposition mechanisms:

$\mathrm{R}_{\mathrm{tot}, 1}=\mathrm{R}_{\mathrm{m}}+\mathrm{R}_{\mathrm{PB}}+\mathrm{R}_{\mathrm{C}, \mathrm{rev}}+\mathrm{R}_{\mathrm{C}, \mathrm{irr}}$

where $\mathrm{R}_{\mathrm{PB}}$ is the resistance due to "Pore Bloking".

The resistances $R_{\text {tot,cw }}$ and $R_{\text {tot,2 }}$ can be expressed according to Eqs. (8) and (9):

$\mathrm{R}_{\mathrm{tot}, \mathrm{cw}}=\mathrm{R}_{\mathrm{m}}+\mathrm{R}_{\mathrm{PB}}$

$\mathrm{R}_{\mathrm{tot}, 2}=\mathrm{R}_{\mathrm{m}}+\mathrm{R}_{\mathrm{PB}}+\mathrm{R}_{\mathrm{C}, \mathrm{rev}}$

Finally, the RIS model is applied in the following way, through Eqs. (10)-(12), in order to compute the different fouling mechanisms:

$\mathrm{R}_{\mathrm{PB}}=\mathrm{R}_{\mathrm{tot}, \mathrm{cw}}-\mathrm{R}_{\mathrm{m}}$

$\mathrm{R}_{\mathrm{C}, \text { irr }}=\mathrm{R}_{\mathrm{tot}, 1}-\mathrm{R}_{\mathrm{tot}, 2}$

$\mathrm{R}_{\mathrm{C}, \mathrm{rev}}=\mathrm{R}_{\mathrm{tot}, 2}-\mathrm{R}_{\mathrm{tot}, \mathrm{cw}}$

\subsection{Viscosity, hydrophobicity, floc dimensions and extracellular content}

Finally, the following main parameters that define the activated sludge features have been measured:

- The viscosity of the mixed liquor was investigated to evaluate the sludge rheology and their role in foaming and fouling. A rotational rheometer (Brookfield digital viscometer, model DV-E) equipped with concentric cylinders and an adapter for low viscosity was used to estimate the mixer liquor viscosity under constant temperature $\left(20^{\circ} \mathrm{C}\right)$.

- For the hydrophobicity of mixed liquor the Rosenberg's method was applied [19].

- The floc size distribution of the sludge suspension was determined by using a Malvern Mastersizer 2000 instrument (Malvern Instruments Ltd., Worcestershire, UK) with a detection range of $0.02-2000 \mu \mathrm{m}$. The characteristic diameters $\mathrm{d}_{10}, \mathrm{~d}_{90}$ and $\mathrm{d}_{\mathrm{m}}$ (average) were determined.

- The total EPSs $\left(\mathrm{EPS}_{\mathrm{T}}\right)$ were evaluated by using the "heating method" $[1,4,20]$, which allows the achievement of the soluble fraction of EPS $\mathrm{T}_{\mathrm{T}}$ (SMPs) as well as the bound fraction $\mathrm{EPS}_{\text {bound. }}$. In order to measure the protein and carbohydrate contents, the extracted bound EPSs and SMPs were analyzed using Lowry's and Anthrone's methods, respectively $[21,22]$. In particular, in this work the sum of protein and carbohydrate content was considered as:

$\mathrm{EPS}_{\mathrm{T}}=\left[\mathrm{EPS}_{\text {bound, } \mathrm{P}}+\mathrm{EPS}_{\text {bound, } \mathrm{C}}\right]+\left[\mathrm{SMP}_{\mathrm{P}}+\mathrm{SMP}_{\mathrm{C}}\right]$

where the subscript symbol " $\mathrm{P}$ " or " $\mathrm{C}$ " indicates the relative content of proteins or carbohydrates in the EPS $\mathrm{T}$ and SMPs, respectively.

\section{Results and discussion}

\subsection{Mixed liquor characterization (EPS, viscosity, floc} dimensions)

Concerning the removal efficiencies, the pilot plant reduced the average influent COD of $326 \mathrm{mg} / \mathrm{L}$ to a median effluent COD concentration of $27 \mathrm{mg} / \mathrm{L}$ (92\% removal) in the Period I, from $421 \mathrm{mg} / \mathrm{L}$ to $18 \mathrm{mg} / \mathrm{L}$ in the Period II (96\% removal), from $401 \mathrm{mg} / \mathrm{L}$ to $14 \mathrm{mg} / \mathrm{L}$ in the Period III (97\% removal). In general, each phase (anoxic and aerobic) contributed to the COD removal, with a similar specific COD removal in both phases.

Regarding the TN removal, different biological performances were observed during each period.

- In the Period I, the average nitrification and denitrification efficiencies were about $71 \%$ and $85 \%$, respectively: the unsatisfying nitrification efficiency was likely due to the low abundance of autotrophic biomass due to low F/M ratio applied, that affected significantly the nitrification efficiency.

- In the Period II, the average nitrification and denitrification efficiencies were about $95 \%$ and $72 \%$, respectively: in this case, the nitrification was complete because the phase of aeration were higher than Period I $\left(t_{\text {aeration }} / t_{\text {cycle }}=0.44\right.$ in Period 2 and 0.33 in Period 1); contrary the efficiency of nitrification was slightly lower (than period II) because now there are more nitrate to denitrified.

- In the Period III, the average nitrification and denitrification efficiencies were about $98 \%$ and $55 \%$, respectively: the unsatisfying denitrification efficiency was strictly dependent on the number of daily cycle (with a $t_{\text {cycle }}$ of 90 min there are 16 cycle per day, significantly higher than 8 cycle per days of period 1 and 2 ); such a circumstance (displacement between aerated and no-aerated phase) significantly affected the total nitrogen removal efficiency, that in period 3 was lower than $60 \%$, as average value

A detailed discussion concerning the removal performance of removal of the plant was reported in [15].

On the other hand, some important observation concerning Mixed liquor characteristics can be done before to discuss foaming and fouling phenomena in IA-MBR.

During the investigated period the average mixed liquor suspended solid MLSS concentrations for the pilot-scale MBR ranged from 5 to $7 \mathrm{~g}_{\mathrm{TSS}} / \mathrm{l}$ and the average percentage of volatile fraction was almost equal to $75 \%$. The observed yield coefficient $\left(Y_{o b s}\right)$ was near to $0.07 \mathrm{gVSSgCOD}^{-1}$. Actually, It's important to underline that the mixed liquor suspended solid MLSS concentration was lower during the initial days ( $\left.<7 \mathrm{~g}_{\mathrm{TSS}} / \mathrm{l}\right)$, due to an excessive sludge withdrawal. Only at the end of Period I, when sludge withdrawals were 
a)

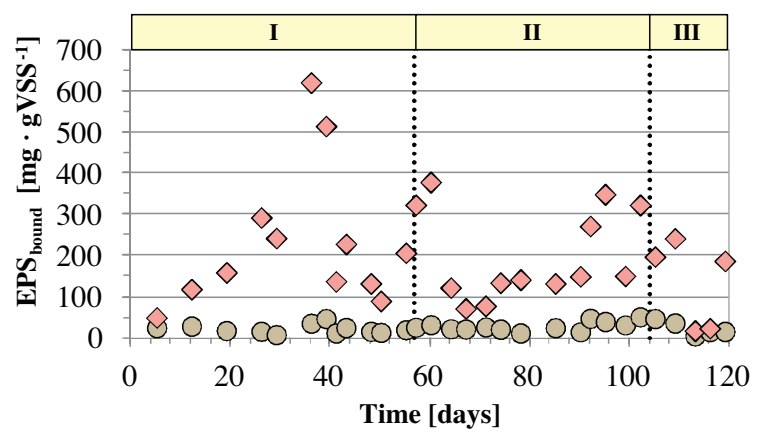

b)

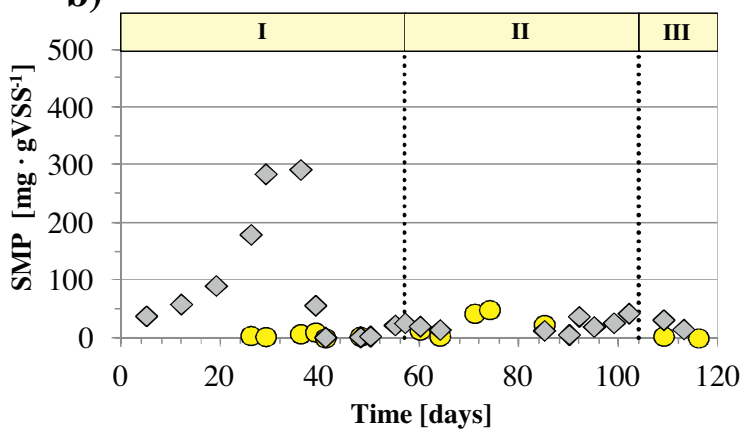

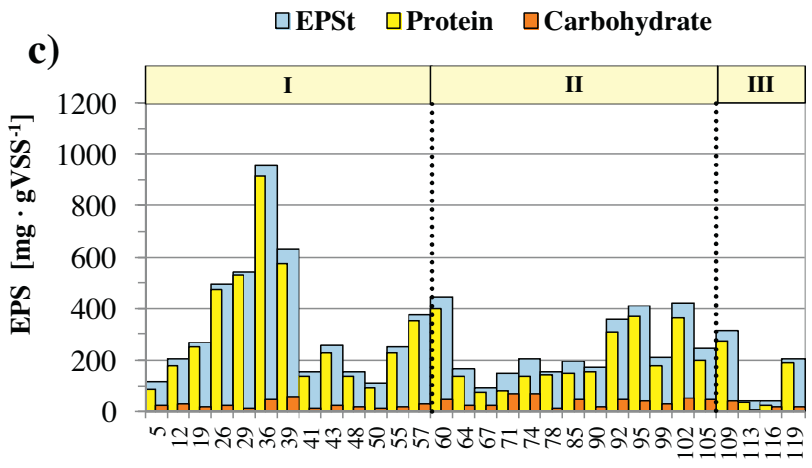

Time [days]

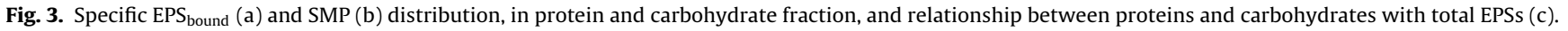

reduced, the MLSS values rose reaching a final value of $7 \mathrm{~g}_{\mathrm{TSS}} / \mathrm{l}$ and thereafter no significant biomass growth has been noticed [15].

The EPSs in the mixed liquor, that were known as key factors in the formation of foaming and fouling in other plants [12,13,23-27],

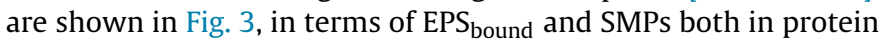
and carbohydrate fractions

The predominance of protein, especially in the form of EPS $S_{\text {bound }}$, could be due to the presence of large quantities of endoenzymes, which were liberated by lysis, and extracellular products in the flocs, depending on microorganism type, substrate properties $[28,29]$ and operating conditions. Furthermore, due to their hydrophobicity, proteins generally have higher affinity for sludge flocs than do polysaccharides [30]. In fact, since the polysaccharides are more readily biodegradable than protein, they are metabolized; contrary, proteins, that are molecularly more complex, tend to adhere to the sludge flocs becoming the main components of $\mathrm{EPS}_{\text {bound }}$. In general, the EPSs formation is favored in IA conditions because the alternation of aerated no-aerated represent a stress factor for microorganisms, which could lead to cellular autolysis [5].

In particular, until day 36 in the Period I $\left(t_{\text {aeration }} / t_{\text {cycle }}=60 \mathrm{~min} / 180 \mathrm{~min}\right)$ high values of $\mathrm{EPS}_{\mathrm{T}}$ were observed due to acclimation of inoculated biomass (collected from a CASP) to the new IA condition. Subsequently the EPS decreased, denoting an acclimatization of biomass to the regime of alternation of anoxic/oxic phases. At the beginning of Period II $\left(t_{\text {aeration }} / t_{\text {cycle }}=80 \mathrm{~min} / 180 \mathrm{~min}\right)$, there was a further decrease of $\mathrm{EPS}_{\mathrm{T}}$ that was likely due to a different metabolic behavior of the biomass [31]. However, in the following days of Period II, a new biomass adaptation occurred with a gradual increase of $\mathrm{EPS}_{\mathrm{T}}$.

Finally, the Period III $\left(t_{\text {aeration }} / t_{\text {cycle }}=30 \mathrm{~min} / 90 \mathrm{~min}\right)$ was characterized by a further decrease of $\mathrm{EPS}_{\mathrm{T}}$ due to the reduction of the anoxic time per cycle, with a subsequent metabolic inhibition.
Finally, Fig. 4a shows the trends of viscosity and hydrophobicity during the three periods; these variables are strictly related to the contents of polysaccharides and proteins, respectively. In this context, the concentration of polysaccharides results correlated well to the viscosity of the mixed liquor (Fig. 4b). On the other hand, in Fig. 4c the correlation between protein content and

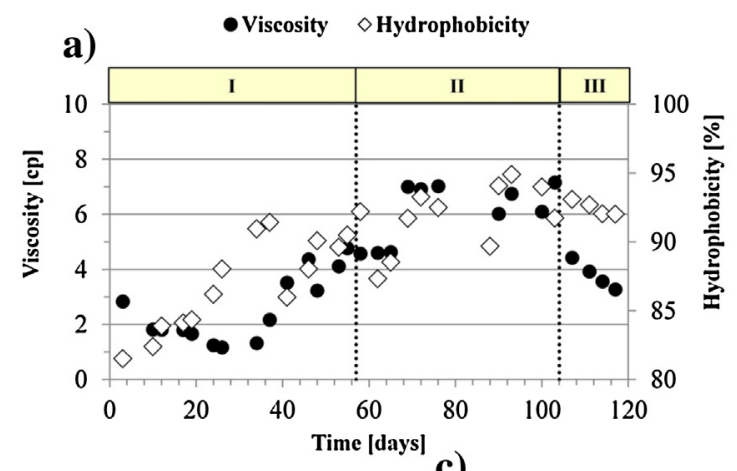

b)

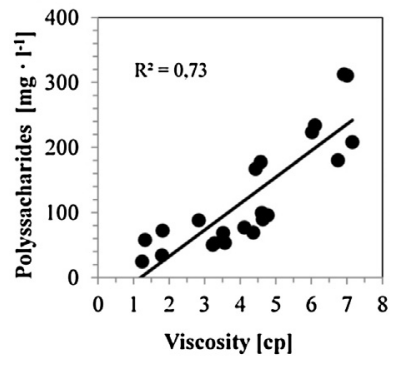

c)

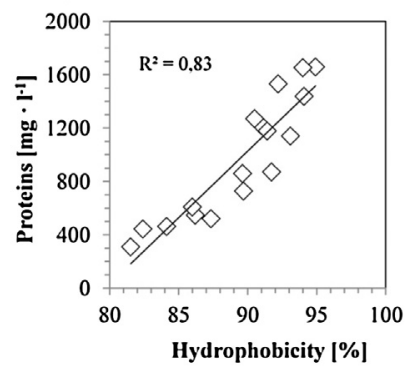

Fig. 4. Distribution of viscosity and hydrophobicity of mixed liquor (a); correlations between polysaccharides and viscosity (b) and between proteins and hydrophobicity (c). 


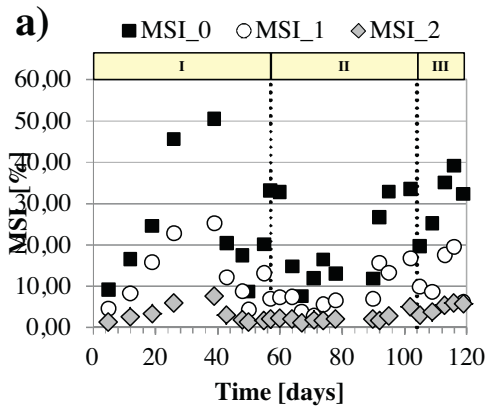

d)

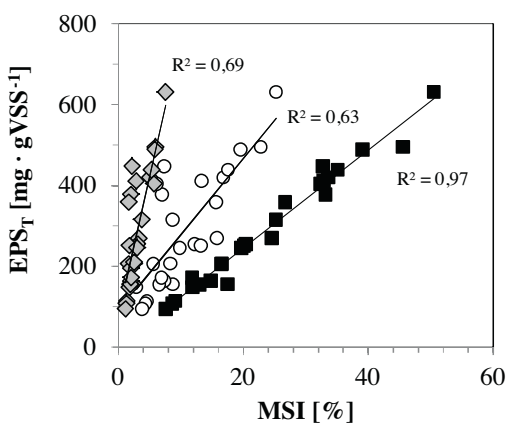

b)

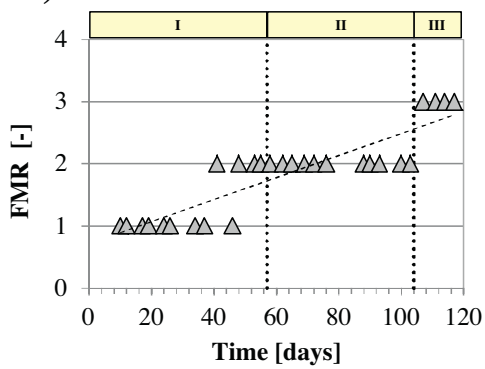

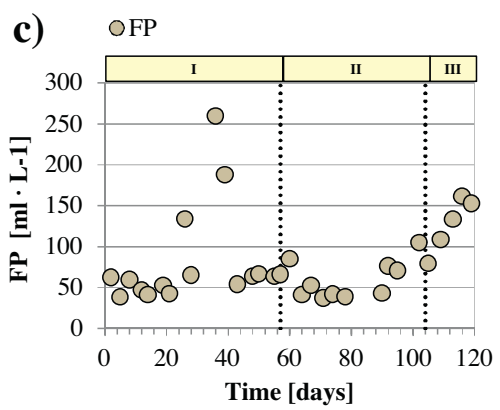

e)

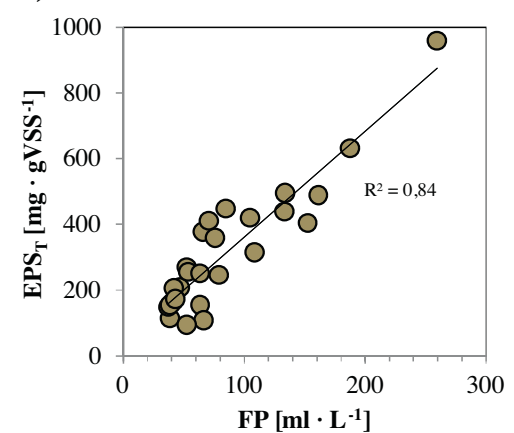

Fig. 5. Modified Scum Index (MSI) (a), Foam Rate $\left(\mathrm{FM}_{R}\right)(\mathrm{b})$, Foam Power (FP) (c), and correlations MSI-EPS $(d)$ and FP-EPS $_{\mathrm{T}}(\mathrm{e})$.

hydrophobicity are reported. In general, the hydrophobicity is coupled to high protein concentration in the mixed liquor, and this circumstance reduces the sludge aggregation [32].

\subsection{Foaming phenomenon analysis}

The results of the Foam Tests, shown in Fig. 5, are representative for samples taken at the end of the aerobic phase.

During Period I, the $\mathrm{MSI}_{0}$ (Fig. 5a) increased until 50\% (day 39th) according to the increase of $\mathrm{EPS}_{\mathrm{T}}$. Subsequently, it decreased to values in the range of $10-20 \%$ at the end of Period I. Similarly, in the Period II, the variation of $\mathrm{MSI}_{0}$ is correlated to EPSs variation: initially $\mathrm{MSI}_{0}$ decreased (until day 90 th) and then increased to about $35 \%$. In period III, the $\mathrm{MSI}_{0}$ decreased to about $20 \%$. Thus, in agreement with previous studies $[9,12]$, also in an IA-MBR the general trend of $\mathrm{MSI}_{0}$ is correlated with the variation of $\mathrm{EPS}_{\mathrm{S}}$ in the bioreactor. Contrarily, after the complete process of "purification" the effect of EPS sas "masked". More specifically, the MSI 2 was less affected by the EPS , and showed a trend similar to that of filamentous microorganisms. The correlation between $\mathrm{MSI}_{2}$ and the level of filamentous abundance is discussed in the next paragraph.

The quality and stability of the foam layer, in terms of $\mathrm{FM}_{R}$ and FP tests respectively, are shown in Fig. $5 \mathrm{~b}$ and c. Both parameters increased continuously during the whole monitoring period: this was probably due to the stabilizing effect of the filamentous that were selected during the experiment (see next sections).

In general, using the previous $\mathrm{FM}_{\mathrm{R}}$ classification, in the Period I and II the foam appeared as "fragile and decreasing if the aeration ceased". On the other hand, in Period III the foam layer was $3-8 \mathrm{~cm}$ in height with "infrequent regular film formation, having 10-30 s stability, and with both film and foam being semi-stable upon aeration being halted".

Concerning Fig. $5 c$, the results shown that the trend of FP started from a value next to about $50 \mathrm{ml} \mathrm{L}^{-1}$, then it rapidly increased to over $250 \mathrm{ml} \mathrm{L}^{-1}$ (day 36), in correspondence of a simultaneous increase of EPS $\mathrm{T}_{\mathrm{T}}$ (mainly protein fraction). Subsequently, the value decreased to about $50 \mathrm{ml} \mathrm{L}^{-1}$ by day 92 . Finally, at the end of period
II and during period III, there was an increase to $150 \mathrm{ml} \mathrm{L}^{-1}$ and this latter trend is mainly due to the filamentous microorganisms, as further discussed.

Fig. 5d, e summarize the correlation between $\mathrm{EPS}_{\mathrm{T}}$, MSI and FP data, confirming that the EPS are a key factor in the foaming. In detail, the correlation between MSI and $\mathrm{EPS}_{\mathrm{T}}$ became progressively weaker going from $\mathrm{MSI}_{0}$ to $\mathrm{MSI}_{2}$ (Fig. $5 \mathrm{~d}$ ). On the other hand, the absence of significant correlations between $\mathrm{MSI}_{2}$ and $\mathrm{EPS}_{\mathrm{S}}$ confirms that the purification step reduces the effect of EPSs on foaming, in favor of the contribution of filamentous bacteria [9,13]. In particular, when the mixed liquor was purified from scum during the foaming tests, the major amount of EPS was removed with the scum and so the correlation between the extracellular polymeric substances and the subsequent scum indexes became gradually less important.

Finally, Fig. 5e shows that also the EPS and FP are strongly correlated. The polymeric and jelly nature of EPS, involves the production of ever more persistent biological foam under aerobic conditions, the greater is the concentration of extracellular polymeric substances. So, FP is a parameter that satisfactorily describes the "probability" of the mixed liquor foaming in all operative conditions (such as caused by only EPS, or coupled EPS with filamentous bacteria).

\subsection{Filamentous bacteria in IA-MBR}

Filamentous bacteria play an important role in the development of sludge features and membrane permeability. Thus, the analysis of filamentous bacteria in the sludge suspension, shown in Fig. 6a, provides useful information. In this context, the microscopic observations and investigations according to Jenkins et al. [18] carried out since day 44, highlighted the presence of three dominant species of filamentous bacteria: Eikelboom Type 0092, Microthrix parvicella and, in smaller quantities, Nocardioforms.

The Eikelboom Type 0092 ("not famous" bacteria) as one of the dominant species is in agreement with other studies [9,29,33,34]. In particular, the proliferation of this filamentous bacterium was 
a)

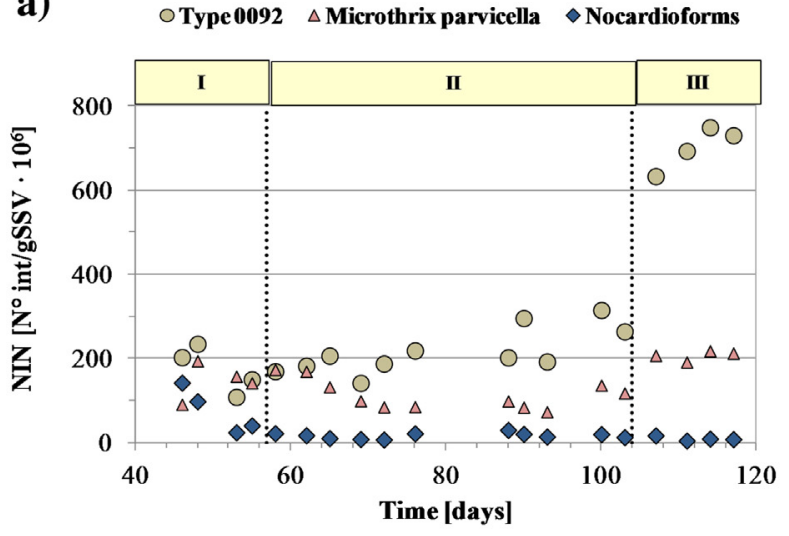

a1) Type 0092

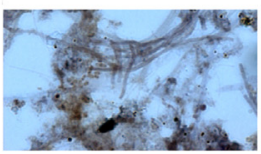

a2) Microthrix parvicella

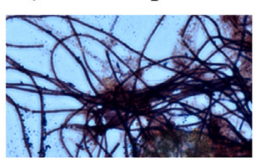

a3) Nocardia

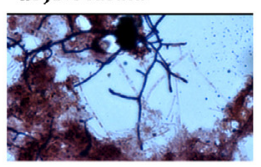

b)

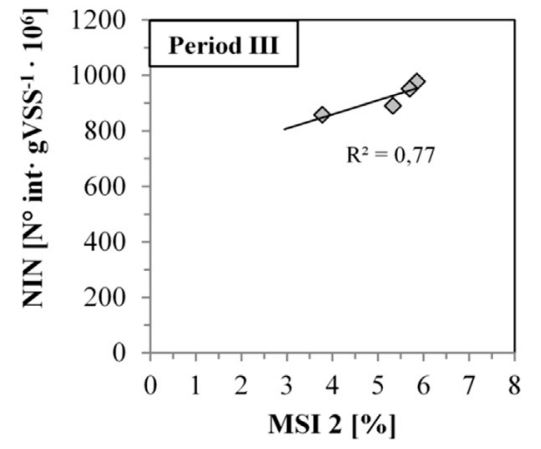

c)

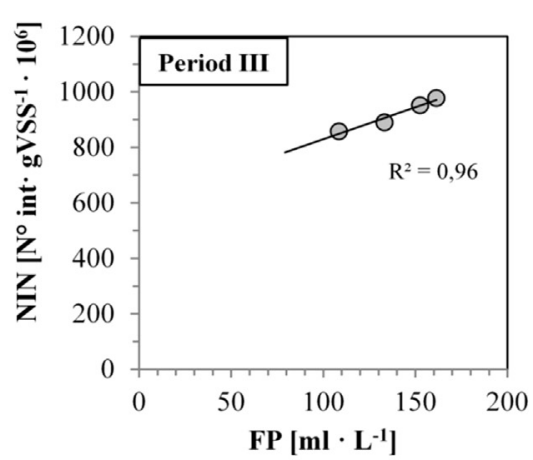

Fig. 6. Trend of filamentous bacteria (a) (with a1-a3 microscopic observations) and their correlations with $\mathrm{MSI}_{2}$ (b) and $\mathrm{FP}$ (c).

favored by the operating conditions imposed in the IA-MBR and by the lack of dissolved oxygen during the anoxic phases, especially in the Period III.

Correlations between the development of total filamentous bacterial species and the Scum Index and the foam power in Period III are also shown in Fig. 6(b and c). It is important to underline that, conversely to the correlation between MSI and EPSs, the best correlation between MSI and NIN was observed in Period III with $\mathrm{MSI}_{2}$. This result confirms the results of previous experiments [9] and previous observations: in general, the data show a significant correlation after purification steps. Furthermore, in the Period III, the potential of foaming is also coupled to filamentous microorganisms, as confirmed by the correlation between FP and NIN (Fig. 6c).

In general, in an IA-MBR, the main foam-forming bacteria growth strongly depends on the alternation of the aerobic/anoxic phases.

- Fewer cycles per day and higher duration of the anoxic phase for single cycle, determined a greater production of EPS, which was the main cause of foaming in Periods I and II.

- On the other hand, a higher number of cycles per day, as in Period III, stimulate a proliferation of different filamentous microorganisms that become a key foam-forming factor in term of stability and foam potential.

\subsection{Membrane fouling analysis and relation with foaming}

The variation of the total resistances to filtration is reported in Fig. 7a. The total hydraulic resistance trend was strongly influenced by physical cleanings, which allowed a partial recovery of permeability and the estimation of specific resistances. No prevailing fouling mechanism, between the reversible and irreversible fouling, was observed from the analysis and comparison of the specific fouling resistances (Fig. 7b). Only in the Period III, the irreversible fouling mechanisms, in terms of $\mathrm{R}_{\mathrm{Cirr}}$ and $\mathrm{R}_{\mathrm{PB}}$, were dominant.

On the other hand, Fig. 7c underlines the important role of bound and soluble EPS on the membrane fouling development. More specifically, the histogram reports the singular ratio between each factor (EPSs, SMPs, $\mathrm{R}_{\mathrm{PB}}, \mathrm{R}_{\text {Cake }}$ ) and the total fraction of $\mathrm{EPS}_{\mathrm{T}}$ or $\mathrm{R}_{\mathrm{T}}$. In this context, Fig. 7c shows an opposite trend for the three periods with regard to EPS $_{\text {bound }}$ and SMP. From Period I to period III, the microorganisms modify their metabolism, decreasing their cellular autolysis (so implying lower release of SMP) [5,31] and increasing the production of exopolymers as storage substrate in the form of EPS $_{\text {bound }}$.

Particularly, in Period I, which has a cycle time of $180 \mathrm{~min}$ with 120 min without aeration, biomass is subjected to a higher metabolic stress than in the remaining two periods. Successfully, there was a slight increase of bound EPS $_{\text {bound }}$ fraction (from $77 \%$ in Period I to 96\% in Period III), which corresponds to an equally small decrease of SMP (from $23 \%$ in period I to $4 \%$ in period III). Contemporarily, an increase of irreversible fouling, both as irreversible cake $\left(R_{\text {cake,irr }}\right)$ and as pore blocking $\left(R_{P B}\right)$ was observed at the expense of a decrease in the reversible fouling $\left(R_{\text {cake,rev }}\right)$.

The fouling from irreversible cake is attributable to the production of EPS ${ }_{\text {bound }}$, which gives a gelatinous consistency to the cake that can be removed with a physical cleaning.

The concomitant increase of pore blocking is probably due to deflocculation which typically occurs in a MBR system, as discussed in the following, and which involves floc disintegration, with a possible occlusion of the membrane pores by dispersed microorganisms and soluble products.

Regarding the fouling rate (Fig. 8a) expressed as increase in the total resistance over time, it is greater in the first period because the low concentration of TSS in mixed liquor avoided the formation of a cake with a pre-filter effect [15]. Indeed, the subsequent 


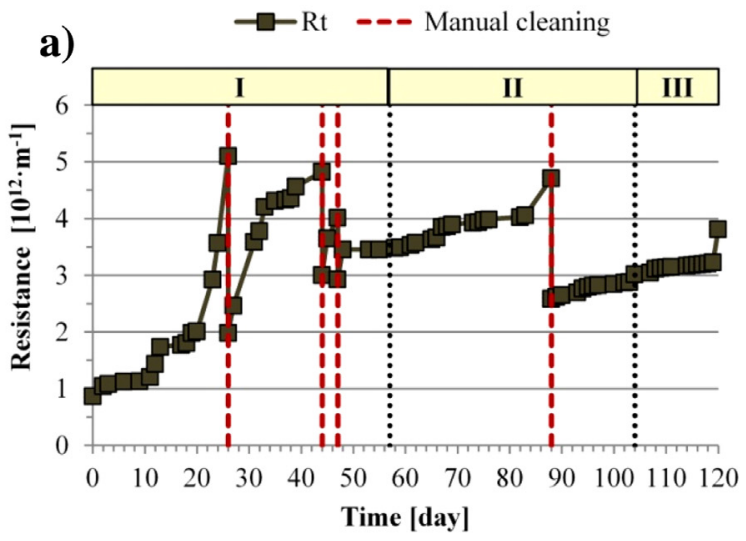

b)

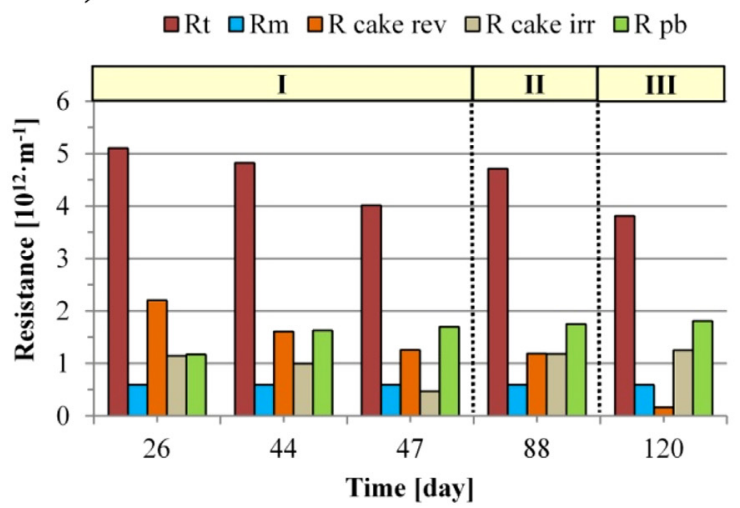

c) 口SMP/EPSt $\quad$ EEPSbound/EPSt $\quad \square$ Rc,rev/Rt $\quad$ Rc,irr/Rt $\quad$ Rpp/Rt

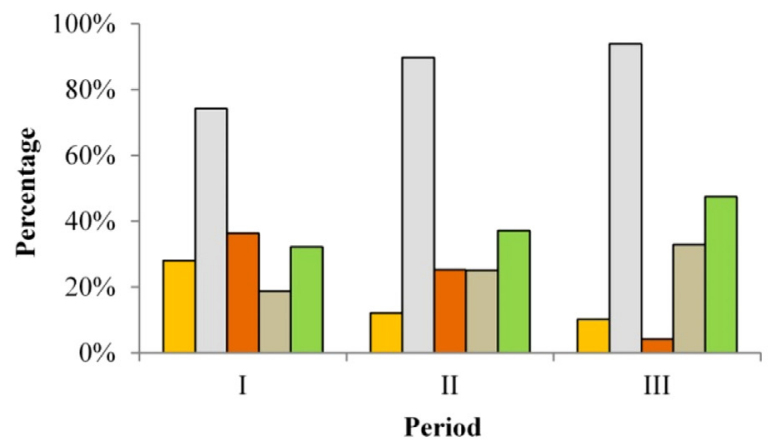

Fig. 7. Total resistance fouling (a), specific resistances (b) and influence of SMPs and EPS ${ }_{\text {bound }}$ on fouling mechanism (c).

development of a cake layer, mainly made of irreversible cake, implied a considerable decrease of fouling rate for the remaining days of experimentation. Furthermore, the fouling rate is closely related to the protein content of the mixed liquor expressed by the ratio Proteins/Polysaccharides (PN/PS), as shown in Fig. 8b. Due to their hydrophobic nature (Fig. 4c), proteins tend to adhere to the surface of the flocs, effectively constituting EPS $_{\text {bound }}$, and contributing to the irreversible cake deposition.

\subsection{Analysis of the floc dimensions}

The results of the morphology observations are reported in Fig. 9a, where $d_{m}$ trends are shown for each phase as well as the $\mathrm{d}_{10}$ and the $\mathrm{d}_{90}$ data.

In general, the data confirm that in the MBR the biological aggregates are smaller than flocs in a Conventional Activated Sludge Plant. This is due to the low organic loading rate conditions, and to the high turbulence in membrane bioreactors [35-37]. More
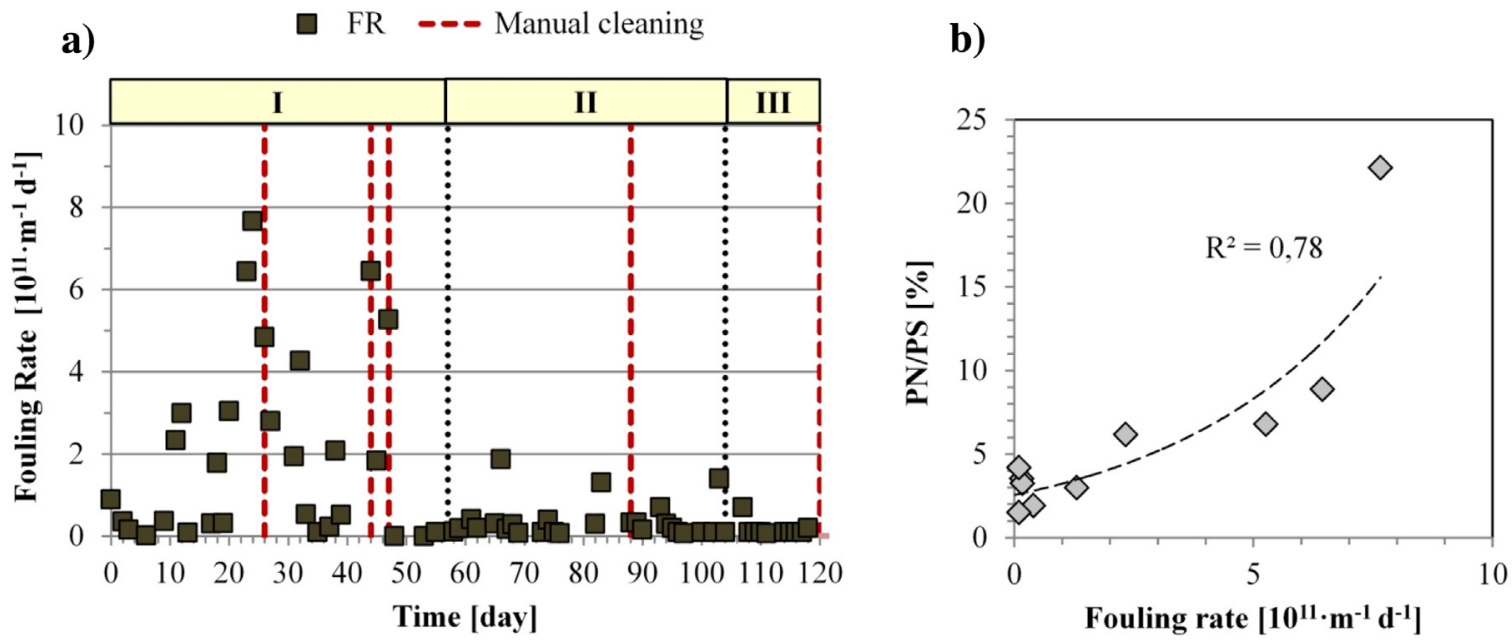

Fig. 8. Fouling rate (a) and correlation with PN/PS (b). 

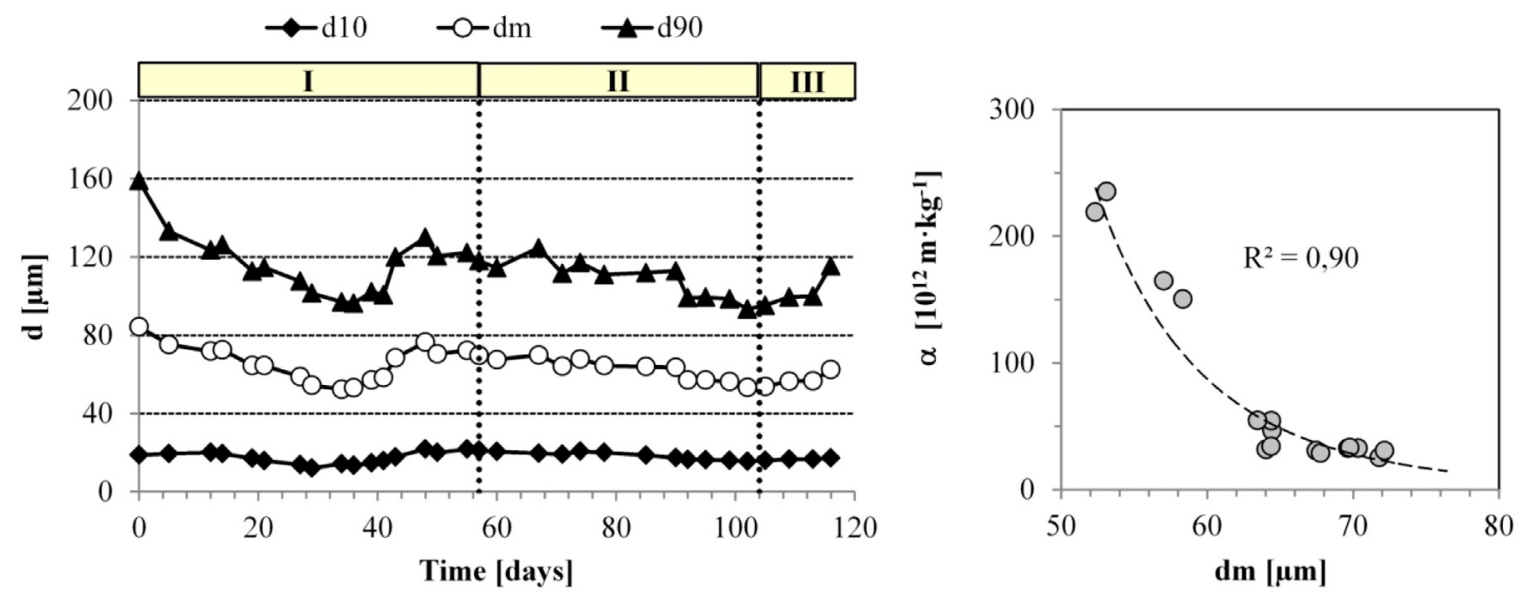

Fig. 9. Floc dimensions variations (a) and correlation between specific cake resistance to filtration and the mean floc dimensions (b).

specifically, throughout the three periods, there was a slight sludge de-flocculation. In particular, in Period I, de-flocculation occurred until day 36th with a partial re-flocculation occurred at the end of this period due to the increase of EPSs in the bioreactor (see Fig. 4a). The Period II was characterized by a slight de-flocculation, while in period III a new re-flocculation was noted, partially due to filamentous microorganisms, which act as bridges for the formation of new sludge flocs.

Consequently, the specific cake layer resistance $(\alpha)$ was influenced by de-flocculation (Fig. 9b). In particular, the superficial cake deposition increased when the floc size decreased. In this
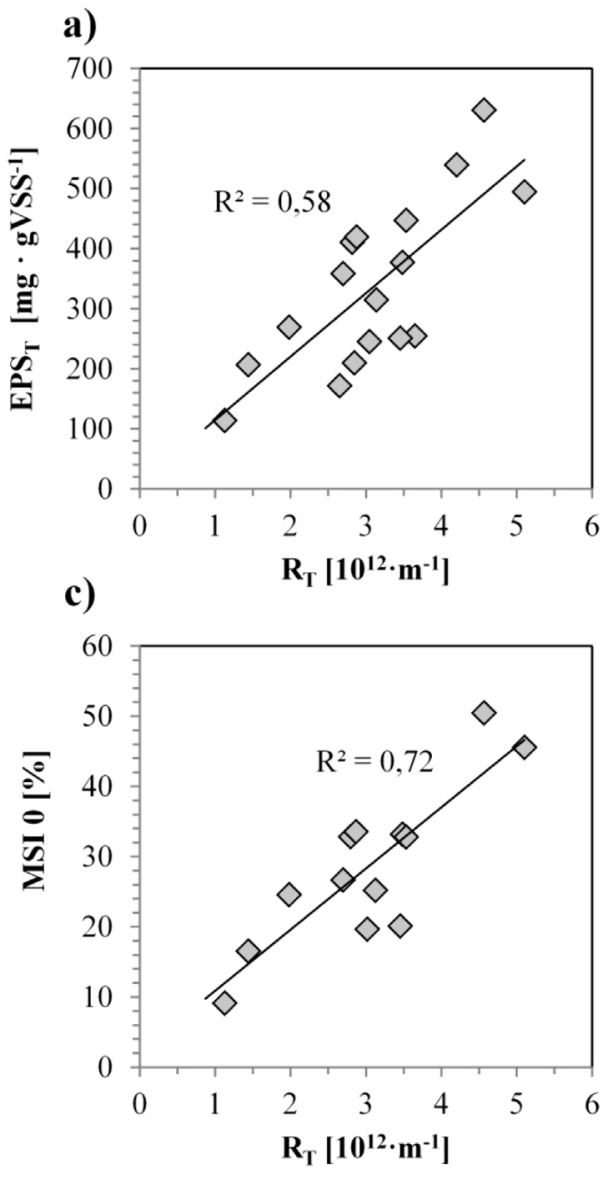

circumstance, the permeability of the resulting cake layer was strongly affected by the presence of filamentous microorganisms or excessive floc hydrophobicity and sludge viscosity.

3.6. Consideration on the relationship between foaming and fouling

In Fig. 10, all correlation between the main operational parameter (EPS, and NIN) and specific fouling and foaming measurement (MSI, Resistances), are shown.
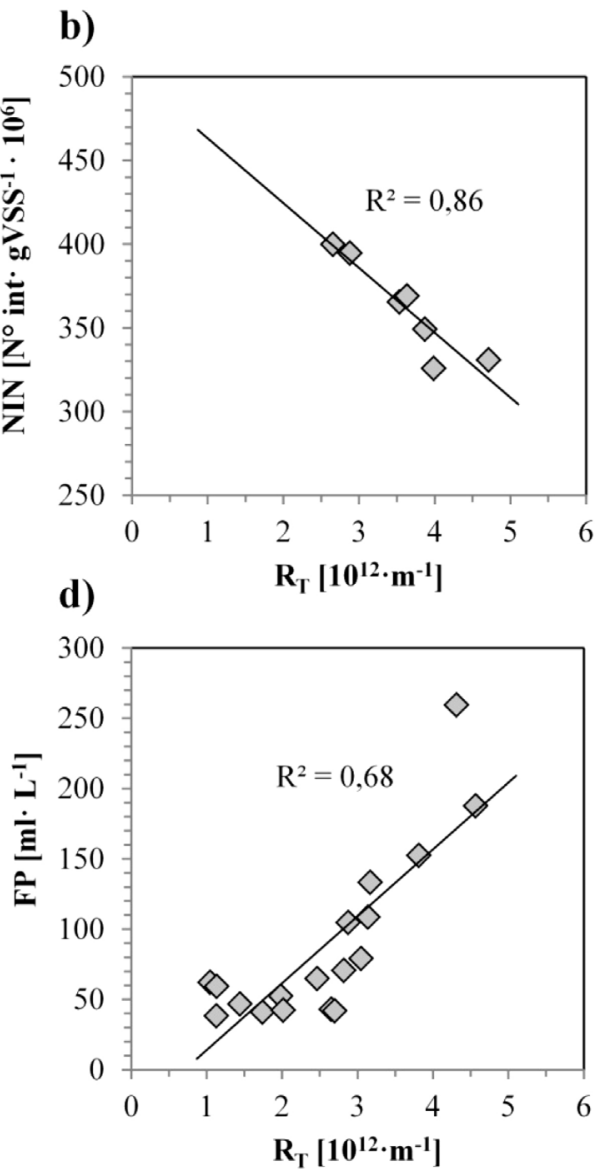

Fig. 10. Correlation between $R_{T}$ and: $\operatorname{EPS}_{T}(a)$, filamentous microorganisms (b), modified scum index (c) and foam power of scum (d). 
In general, the high production of extracellular polymeric substances (Period I and II) involves the formation of a very hydrophobic sludge that implies the formation of compact cake layer, improving its pre-filtration action (Fig. 10a). On the other hand, the filamentous bacteria (Fig. 10b) promote the bridging between the cellular aggregates and the formation of a swollen cake with a reduction of the pre-filter effect (Period III).

Finally, there was similar correlation between $\mathrm{MSI}_{0}$ and FP with the $\mathrm{R}_{\mathrm{t}}$ (Fig. 10c and d). This indicates that the phenomena of foaming and fouling are not independent but interconnected by means of EPSs. Indeed, an increase of foaming quantity (in terms of $\mathrm{MSI}_{0}$ ) and potential (in terms of FP) inevitably involves a worsening of the permeability of the membrane. This result is apparently in disagreement with the view taken by the authors Cosenza et al. [13], that affirmed that membrane fouling tend to decrease if foaming increase. Likely, the difference is due to the higher presence of overall EPS bound in the IA-MBR, which contribute to the production of a higher quantity of foam. Furthermore, in the current work, the foaming in the IA-MBR system was mainly due to two different causes: first to EPSs (Period I and II) and subsequently (Period III) to filamentous bacteria and EPSs together. Contrarily, in the experience of Cosenza and coauthors, the foaming was mainly correlated to EPSs contribution (with a very low filamentous abundance). In any case, it is important to remember that the foam "persistence" is related to the geometric features of Bioreactor, which are different in both experimentations.

\section{Conclusions}

The foam formation occurred spontaneously in the IA-MBR, with high values of MSI (>30\%) and FP $\left(>150 \mathrm{~mL} \mathrm{~L}^{-1}\right)$. In general, the results show that extracellular polymeric substances play key roles in foam and fouling. Furthermore, if the high concentration of EPS is coupled to the presence of filamentous bacteria (as it occurs with short duration of the aeration-no aeration cycles) the foaming phenomenon worsens. For the analyzed case study, in Period I and II (both with a cycle duration of $180 \mathrm{~min}$ ) the foam was due to EPSs production, as shown by the $\mathrm{MSI}_{0}$ trend. In these periods, there are fewer aeration cycles per day but the anoxic phase for each cycle is longer. On the other hand, the higher number of cycles per day in Period III (duration of the cycle of $90 \mathrm{~min}$ ), despite the shorter duration of the anoxic phase for each cycle, promoted the proliferation of filamentous bacteria that became a key foam-forming factor, as confirmed by FP-NIN correlation.

However, this study provides a new outlook about the role of EPS in the foaming for MBRs and also a new insight into the membrane fouling mechanism.

\section{Acknowledgements}

This research was funded by the National Research Project PRIN 2009 (Project Title: Experimental analysis on MBR systems to study and to realize a model of fouling including the physical and microbiological features of sludge and the operational conditions that influence this phenomenon CUP B71J11000610001); Italian Ministry of Education, University and Research.

\section{References}

[1] S. Judd, The MBR Book: Principles and Applications of Membrane Bioreactors for Water and Wastewater Treatment, second edition, Elsevier, Oxford, UK, 2011

[2] F. Meng, S.R. Chae, A. Drews, M. Kraume, H.S. Shin, F. Yang, Recent advances in membrane bioreactors (MBRs): membrane fouling and membrane material, Water Res, 43 (2009) 1489-1512.

[3] A. Drews, Membrane fouling in membrane bioreactors-characterisation contradictions, cause and cures, J. Membr. Sci. 363 (2010) 1-28.
[4] P. Le-Clech, V. Chen, T.A.G. Fane, Fouling in membrane bioreactors used in wastewater treatment, J. Membr. Sci. 284 (2006) 17-53.

[5] H. Lin, M. Zhang, F. Wang, F. Meng, B.-Q. Liao, H. Hong, J. Chen, W. Gao, A critical review of extracellular polymeric substances (EPSs) in membrane bioreactors: characteristics, roles in membrane fouling and control strategies, J. Membr. Sci. 460 (2014) 110-125.

[6] Z. Ahmed, J. Cho, B.R. Lim, K.G. Song, K.H. Ahn, Effects of sludge retention time on membrane fouling and microbial community structure in a membrane bioreactor, J. Membr. Sci. 287 (2007) 211-218.

[7] G. Mannina, G. Di Bella, Comparing two start-up strategies for MBRs: experimental study and mathematical modelling, Biochem. Eng. J. 68 (2012) (2012) 91-103

[8] F. Delrue, A.E. Stricker, M. Mietton-Peuchot, Y. Racault, Relationships between mixed liquor properties, operating conditions and fouling on two full-scale MBR plants, Desalination 272 (2011) 9-19.

[9] G. Di Bella, M. Torregrossa, Foaming in membrane bioreactors: identification of the causes, J. Environ. Manage. 128 (2013) 453-461.

[10] G. Di Bella, M. Torregrossa, G. Viviani, The role of EPS concentration in MBR foaming: analysis of a submerged pilot plant, Bioresour. Technol. 102 (2011) 1628-1635.

[11] R.J. Davenport, T.P. Curtis, Are filamentous mycolata important in foaming? Water Sci. Technol. 46 (2002) 529-533.

[12] J. Nakajima, I. Mishima, Measurement of foam quality of activated sludge in MBR process, Acta Hydrochim. Hydrobiol. 33 (2005) 232-239.

[13] A. Cosenza, G. Di Bella, G. Mannina, M. Torregrossa, The role of EPS in fouling and foaming phenomena for a membrane bioreactor, Bioresour. Technol. 147 (2013) 184-192.

[14] P. Nardelli, G. Gatti, A.L. Eusebi, P. Battistoni, F. Cecchi, Full-scale application of the alternating oxic/anoxic process: an overview, Ind. Eng. Chem. Res. 48 (2009) 3526-3532.

[15] M. Capodici, G. Di Bella, D. Di Trapani, M. Torregrossa, Pilot scale experiment with MBR operated in intermittent aeration condition: analysis of biological performance, Bioresour. Technol. 177 (2015b) (2015) 398-405.

[16] APHA, Standard Methods for the Examination of Water and Wastewater APHA, AWWA and WPCF, Washington DC, USA, 2005.

[17] L.L. Blackall, A.E. Harbers, P.F. Greenfield, A.C. Hayward, Activated sludge foams: effects of environmental variables on organism growth and foam formation, Environ. Technol. 12 (1991) 241-248.

[18] D. Jenkins, M.G. Richard, G.T. Daigger, Manual on the Causes and Control of Activated Sludge Bulking, Foaming, and Other Solids Separation Problems, 132-147, Third edition, IWA Publishing, London, UK, 2004.

[19] M. Rosenberg, D. Gutnick, E. Rosenberg, Adherence of bacteria to hydrocarbons: a simple method for measuring cell-surface hydrophobicity, FEMS Microbiol. Lett. 9 (1980) 29-33.

[20] X. Zhang, P.L. Bishop, B.K. Kinkle, Comparison of extraction methods for quantifying extracellular polymers in biofilms, Water Sci. Technol. 39 (1999) 211-218.

[21] O.H. Lowry, N.J. Rosebrough, A.L. Farr, R.J. Randall, Protein measurement with the Folin phenol reagent, J. Biol. Chem. 193 (1951) 265-275.

[22] M. Dubois, K.A. Gilles, J.K. Hamilton, P.A. Rebers, F. Smith, Colorimetric method for determination of sugars and related substances, Anal. Chem. 28 (1956) 350-356

[23] B. Frolund, T. Griebe, P.H. Nielsen, Enzymatic activity in the activated-sludge floc matrix, Appl. Microbiol. Biotechnol. 43 (1995) 755-761.

[24] R. Bura, M. Cheung, B. Liao, J. Finlayson, B.C. Lee, I.G. Droppo, G.G. Leppard, S.N. Liss, Composition of extracellular polymeric substances in the activated sludge floc matrix, Water Sci. Technol. 37 (1998) 325-333.

[25] Y. Liu, H.H.P. Fang, Influences of extracellular polymeric substances (EPS) on flocculation settling, and dewatering of activated sludge, Crit. Rev. Environ. Sci. Technol. 33 (2003) 237-273.

[26] H. Nagaoka, H. Akoh, Decomposition of EPS on the membrane surface and its influence on the fouling mechanism in MBRs, Desalination 231 (2008) $150-155$

[27] Y. Tian, Behaviour of bacterial extracellular polymeric substances from activated sludge: a review, Int. J. Environ. Pollut. 32 (2008) 78-89.

[28] D.T. Sponza, Extracellular polymer substances and physicochemical properties of flocs in steady- and unsteady-state activated sludge systems, Process Biochem. 37 (2002) 983-998.

[29] F.G. Meng, H.M. Zhang, F.L. Yang, Y.S. Li, J.N. Xiao, X.W. Zhang, Effect of filamentous bacteria on membrane fouling in submerged membrane bioreactor, J. Membr. Sci. 272 (2006) 161-168.

[30] A. Massé, M. Spérandio, C. Cabassud, Comparison of sludge characteristics and performance of a submerged membrane bioreactor and an activated sludge process at high solids retention time, Water Res. 40 (2006) 2405-2415.

[31] S.-H. Hong, W.-N. Lee, H.-S. Oh, K.-M. Yeon, B.-K. Hwang, C.-H. Lee, I.-S. Chang, S. Lee, The effects of intermittent aeration on the characteristics of bio-cake layers in a membrane bioreactor, Environ. Sci. Technol. 41 (2007) 6270-6276.

[32] M.C. van Loosdrecht, J. Lyklema, W. Norde, G. Schraa, A.J. Zehnder, The role of bacterial cell wall hydrophobicity in adhesion, Appl. Environ. Microbiol. 53 (1987) 1893-1897.

[33] H. Lemmer, G. Lind, E. Müller, M. Schade, Non-famous scum bacteria: biological characterization and troubleshooting, Acta Hydrochim. Hydrobiol. 33 (2005) 197-202.

[34] S.J. You, W.M. Sue, Filamentous bacteria in a foaming membrane bioreactor, J. Membr. Sci. 342 (2009) 42-49. 
[35] F. Durante, G. Di Bella, M. Torregrossa, G. Viviani, Particle size distribution and biomass growth in a submerged membrane bioreactor, Desalination 199 (2006) 493-495.

[36] X. Huang, P. Gui, Y. Qian, Effect of sludge retention time on microbia behaviour in a submerged membrane bioreactor, Process Biochem. 36 (2001) 1001-1006.
[37] M. Spérandio, A. Masse, M.C. Espinosa-Bouchot, C. Cabassud, Characterization of sludge structure and activity in submerged membrane bioreactor, Water Sci.Technol. 52 (2005) 401-408. 